\title{
Fabrication of Nanohybrid Spinel@CuO Catalysts for Propane Oxidation: Modified Spinel and Enhanced Activity by Temperature-Dependent Acid Sites
}

Bin Wang ${ }^{1, \#}$, Guangpeng Yang ${ }^{2, \#}$, Qilei Yang ${ }^{3}$, Bing $\mathrm{Li}^{3}$, Dong Wang*,2, Yue Peng 3 , Junhua $\mathrm{Li}^{3}$, Chunmei Lu${ }^{1}$, John Crittenden ${ }^{2}$

${ }^{1}$ School of Energy and Power Engineering, Shandong University, Jinan 250061, China

2 School of Civil and Environmental Engineering and the Brook Byers Institute for Sustainable Systems, Georgia Institute of Technology, 828 West Peachtree Street, Atlanta, Georgia, 30332, United States

3 State Key Joint Laboratory of Environment Simulation and Pollution Control, National Engineering Laboratory for Multi Flue Gas Pollution Control Technology and Equipment, School of Environment, Tsinghua University, Beijing 100084, China

\# These authors contributed equally to this work.

*Corresponding author.

E-mail address: dwang473@gatech.edu (Dong Wang) 


\section{Contents}

1. Catalyst characterization. $\quad S 4$

2. DFT calculation details. $\quad S 6$

3. Catalyst activity measurement. $\quad S 7$

4. Figure S1. BET isotherms and BJH pore size distribution plots (inset): the (a) $\mathrm{CuFe} @ \mathrm{CuO}$ and CuFeCo@CuO; (b) CuAl@CuO and CuAlCo@CuO. S9

5. Figure S2. XRD patterns of the LDH precursors. $\quad \mathbf{S 1 0}$

6. Figure S3. SAED images of the spinel@CuO catalysts. $\quad S 11$

7. Figure S4. XRD patterns of (a) the spinel samples and (b) $\mathrm{CuO}$ sample.

$S 12$

8. Figure S5. Propane conversion curves and propane conversion to $\mathrm{CO}_{2}$ curves of the physically mixed spinel $+\mathrm{CuO}$ catalysts. $S 13$

9. Figure S6. The initial $\mathrm{H}_{2}$ consumption rate versus inverse temperature of the $\mathrm{CuFe} @ \mathrm{CuO}$ and CuFeCo@CuO catalysts. $\quad S 14$

10. Figure S7. XPS spectra of $\mathrm{Cu} 2 \mathrm{p}$ on the spinel@CuO catalysts. $S 15$

11. Figure S8. XPS spectra of $\mathrm{Al} 2 \mathrm{p}$ on the $\mathrm{CuAl} @ \mathrm{CuO}$ and $\mathrm{CuAlCo} @ \mathrm{CuO}$ catalysts. $S 16$

12. Figure S9. Projected density of states (PDOS) of $\mathrm{Cu} 3 \mathrm{~d}$, Fe 3d, and O 2p orbitals for the $\mathrm{CuFe}$ and $\mathrm{CuFeCo.} \quad \boldsymbol{S 1 7}$

13. Figure S10. Projected density of states (PDOS) of $\mathrm{Cu} 3 \mathrm{~d}, \mathrm{Al} 2 \mathrm{p}$, and $\mathrm{O} 2 \mathrm{p}$ orbitals for the $\mathrm{CuAl}$ and CuAlCo. $S 18$

14. Figure S11. Pyridine-FTIR spectra of the spinel@CuO catalysts at different temperature. 
15. Figure S12. Optimized structure of (a) $\mathrm{CuFe}$, (b) $\mathrm{CuFeCo}$, (c) $\mathrm{CuAl}$, (d) $\mathrm{CuAlCo}$ spinel on side view. The red balls are oxygen, orange balls are copper, deep blue balls are iron, brilliant blue balls are cobalt, and pink balls are aluminium.

16. Figure S13. Optimized structure of (a) $\mathrm{CuFe}$, (b) $\mathrm{CuFeCo}$, (c) $\mathrm{CuAl}$, (d) $\mathrm{CuAlCo}$ spinel on top view. The red balls are oxygen, orange balls are copper, deep blue balls are iron, brilliant blue balls are cobalt, and pink balls are aluminium. 


\section{Catalyst characterization.}

The Brunauer-Emmett-Teller (BET) surface areas were obtained via nitrogen adsorption-desorption at the liquid $\mathrm{N}_{2}(\mathrm{LN})$ temperature $\left(-196{ }^{\circ} \mathrm{C}\right)$ on a TriStar II 3020 apparatus produced by American Micromeritics. Before measurement, the samples were degassed under the vacuum at $300{ }^{\circ} \mathrm{C}$ for $4 \mathrm{~h}$. The pore size distributions were measured by Barrett-Joyner Halenda (BJH) method.

$\mathrm{X}$-ray diffraction $(\mathrm{XRD})$ data of the prepared samples were tested on a Rigaku Xray diffractometer $(\mathrm{D} / \mathrm{max}-2500 \mathrm{PC})$ fitted with a $\mathrm{Cu} \mathrm{K} \alpha$ source $(\lambda=0.15405 \mathrm{~nm}, 40$ $\mathrm{kV}$ and $200 \mathrm{~mA}$ ). The test condition was from 10 to $80^{\circ}$ at a speed of $10^{\circ} \mathrm{min}^{-1}$.

The X-ray photoelectron spectroscopy (XPS) measurements were performed on a ESCALab 220i-XL electron spectrometer with $\mathrm{Al} \mathrm{K}(\mathrm{h} v=1486.6 \mathrm{eV})$ radiation. The base pressure was approximately $3 \times 10^{-9} \mathrm{mbar}$.

TEM experiments were conducted on a FEI Tecnai G2 F20 apparatus operated at an acceleration voltage of $200 \mathrm{kV}$.

Oxygen temperature programmed desorption $\left(\mathrm{O}_{2}-\mathrm{TPD}\right)$ was carried through a Micromeritics Autochem II 2920 apparatus. During the whole test, the gas flow was set to $50 \mathrm{~mL} \mathrm{~min}{ }^{-1}$ all the time. The investigated samples $(50 \mathrm{mg})$ were pretreated at $300{ }^{\circ} \mathrm{C}$ for $1 \mathrm{~h}$ in Ar to remove impurities adsorbed on its surface before measurement. After being cooled to room temperature, the sample first exposed on a $5 \% \mathrm{O}_{2}$ gas flow for 1 $\mathrm{h}$ and then allowed to undergo isothermal desorption under He for $30 \mathrm{~min}$. The TPD test was performed in $\mathrm{He}$ at a rate of $10{ }^{\circ} \mathrm{C} \mathrm{min}^{-1}$ up to $700{ }^{\circ} \mathrm{C}$.

Hydrogen temperature programmed reduction $\left(\mathrm{H}_{2}-\mathrm{TPR}\right)$ was carried through a 
Micromeritics Autochem II 2920 apparatus. The investigated samples (50 mg) were pretreated at $300{ }^{\circ} \mathrm{C}$ for $1 \mathrm{~h}$ in Ar to remove impurities adsorbed on its surface before measurement. The gas flow rate was $50 \mathrm{~mL} \mathrm{~min}{ }^{-1}$. Then, the prepared samples were cooled to $30{ }^{\circ} \mathrm{C}$ in Ar. The samples were measured continuously by a thermal conductivity detector (TCD) from 30 to $900{ }^{\circ} \mathrm{C}$ with $10 \% \mathrm{H}_{2} / \mathrm{Ar}\left(50 \mathrm{~mL} \mathrm{~min}{ }^{-1}\right)$ flow at $10{ }^{\circ} \mathrm{C} \min ^{-1}$.

EPR spectra were collected on a A300-10/12 apparatus. EPR analysis was conducted using DMPO (5, 5-dimethyl-pyrroline N-oxide) as the spin trapping agent. For each sample, the $\mathrm{N}_{2}$ pretreatment was first performed at $350{ }^{\circ} \mathrm{C}$ for $30 \mathrm{~min}$, and then the liquid nitrogen was used to shock cool to $-196^{\circ} \mathrm{C}$ and the spectra were collected.

In situ pyridine-FTIR spectra were collected using a Nicolet 6700 apparatus produced by American Thermo. The experimental procedures are as follows: First, the sample was dried in an oven and ground in a mortar. Then, a certain amount of powder was placed in a tableting die and compressed. Then, the sample (about $10 \mathrm{mg}$ ) pressed into a self-supporting sheet $(11 \mathrm{~nm})$ was loaded into an in-situ infrared sample cell, and treated at $350{ }^{\circ} \mathrm{C}$ under a high vacuum condition of $10^{-4} \mathrm{mmHg}$ for $1 \mathrm{~h}$ to activate the sample. After cooling to $25^{\circ} \mathrm{C}$, the background spectrum was collected. Pyridine was adsorbed for $0.5 \mathrm{~h}$ and then purged for $0.5 \mathrm{~h}$, and the spectra were collected. Raise the temperature to $40^{\circ} \mathrm{C}, 100{ }^{\circ} \mathrm{C}, 200{ }^{\circ} \mathrm{C}, 350^{\circ} \mathrm{C}$ and collect the spectra, respectively. 


\section{DFT calculation details.}

We conducted the density functional theory (DFT) calculations by the Vienna ab initio simulation package (VASP) software. The exchange-correlation was calculated by the Perdew, Burke, and Ernzerhof (PBE). The projector augmented wave (PAW) was adopted to describe core valence interactions with a plane wave cutoff of $500 \mathrm{eV}$. The self-consistent-field (SCF) electronic energies were converged to $10^{-5} \mathrm{eV}$, and atomic forces were converged below $0.03 \mathrm{eV} / \AA$. The integration of the Brillouin zone was performed using a $3 \times 3 \times 1$ Monkhorst-Pack grid (k-points). The most stable ( 3 , 1, 1) crystal plane of the $\mathrm{CuFe}_{2} \mathrm{O}_{4}$ and $\mathrm{CuAl}_{2} \mathrm{O}_{4}$ spinel was chosen for calculations. For the cobalt-doped spinel, the ratio of doped cobalt to trivalent cations was $1: 20$, and the doped cobalt occupied the A and B sites of the spinel. Thus, the four models could be denoted as $\mathrm{CuFe}, \mathrm{CuFeCo}, \mathrm{CuAl}$, and $\mathrm{CuAlCo}$, respectively. The vacuum space along the $z$ direction was set to be $15 \AA$ in order to minimize the interaction between neighboring slab surfaces. The adsorption energy $\left(E_{\mathrm{ad}}\right)$ for propane was calculated as:

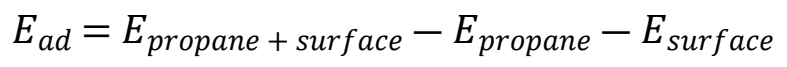

Among them, the $E_{\text {propane+surface }}, E_{\text {propane, }}$ and $E_{\text {surface }}$ were the total energies of a surface with adsorbed propane, the isolated propane, and clean surface, respectively. The oxygen vacancy formation energy $\left(E_{\text {ov }}\right)$ was calculated as:

$$
E_{\text {ov }}=E_{\text {surface }-o v}+1 / 2^{1} E_{O_{2}}-E_{\text {surface }}
$$

Among them, the $E_{\text {surface-ov }}, E_{\mathrm{O} 2}$, and $E_{\text {surface }}$ were the energies of a surface with an oxygen vacancy, a gas-phase $\mathrm{O}_{2}$, and a perfect surface, respectively. 


\section{Catalyst activity measurement.}

The catalytic activity for propane oxidation was measured in a continuous flow fixed-bed quartz microreactor $(\Phi=10.0 \mathrm{~mm})$ using a $0.1 \mathrm{~g}$ sample $(40-60 \mathrm{mesh})$. Reaction conditions: 1000 ppm propane, $5 \% \mathrm{O}_{2}$, balance $\mathrm{N}_{2}$, total flow rate $=100$ $\mathrm{mL} \cdot \mathrm{min}^{-1}, \mathrm{GHSV}=60000 \mathrm{~mL} \cdot \mathrm{g}^{-1} \cdot \mathrm{h}^{-1}$. The concentrations of propane were monitored online by a gas chromatograph (Agilent 7890A) equipped with a TDX-01 column. As the catalytic oxidation reaction reached a steady state, the ratio of propane conversion $(\eta)$ and the pseudofirst-order rate constant $\left(\tau, \mathrm{mL} \cdot \mathrm{g}^{-1} \cdot \mathrm{s}^{-1}\right)$ of the catalytic reaction were calculated according to the following equations:

$$
\begin{gathered}
\eta=\frac{[\text { Propane }]_{\text {in }}-[\text { Propane }]_{\text {out }}}{[\text { Propane }]_{\text {in }}} \times 100 \% \\
\tau=-\frac{V}{W} \times \ln (1-\eta)
\end{gathered}
$$

where $[\text { Propane }]_{\text {in }}$ and [propane $]_{\text {out }}$ are the concentrations of gaseous propane in the inlet and outlet, respectively, $V$ is the total flow rate, and $W$ is the mass of the catalyst (g).

Propane conversion to $\mathrm{CO}_{2}\left(\mathrm{CO}_{2}\right.$ yield, $\left.\mathrm{Y}_{\mathrm{CO} 2}(\%)\right)$ was calculated by the formula as follows:

$$
Y_{\mathrm{CO}_{2}}(\%)=\frac{C_{\mathrm{CO}_{2}}}{3 \times[\text { propane }]_{\text {in }}} \times 100 \%
$$

where $C_{\mathrm{CO} 2}$ represented the $\mathrm{CO}_{2}$ concentration in the outlet gas.

The apparent activation energies were calculated used propane conversion lower than $20 \%$ and following equations: 


$$
\begin{gathered}
X_{\text {propane }}=-\frac{C_{\text {in }}-C_{\text {out }}}{C_{\text {in }}} \times 100 \% \\
\mathrm{r}=-\frac{F}{m \times S_{B E T}} \times \frac{P}{R T} \times \ln \left(1-X_{\text {propane }}\right) \times C_{\text {in }} \\
\ln (\mathrm{r})=-\frac{E_{a}}{R T}+\ln A
\end{gathered}
$$

where $C_{\text {in }}$ and $C_{\text {out }}$ were the propane concentration corresponding to the inlet and outlet, respectively, $F$ was the propane flow rate in unit of $\mathrm{L} \cdot \mathrm{s}^{-1}$, $\mathrm{m}$ was the catalyst mass, $S_{B E T}$ was the catalyst surface area, and $E_{a}$ was the apparent activation energy $\left(\mathrm{KJ} \cdot \mathrm{mol}^{-1}\right)$. 

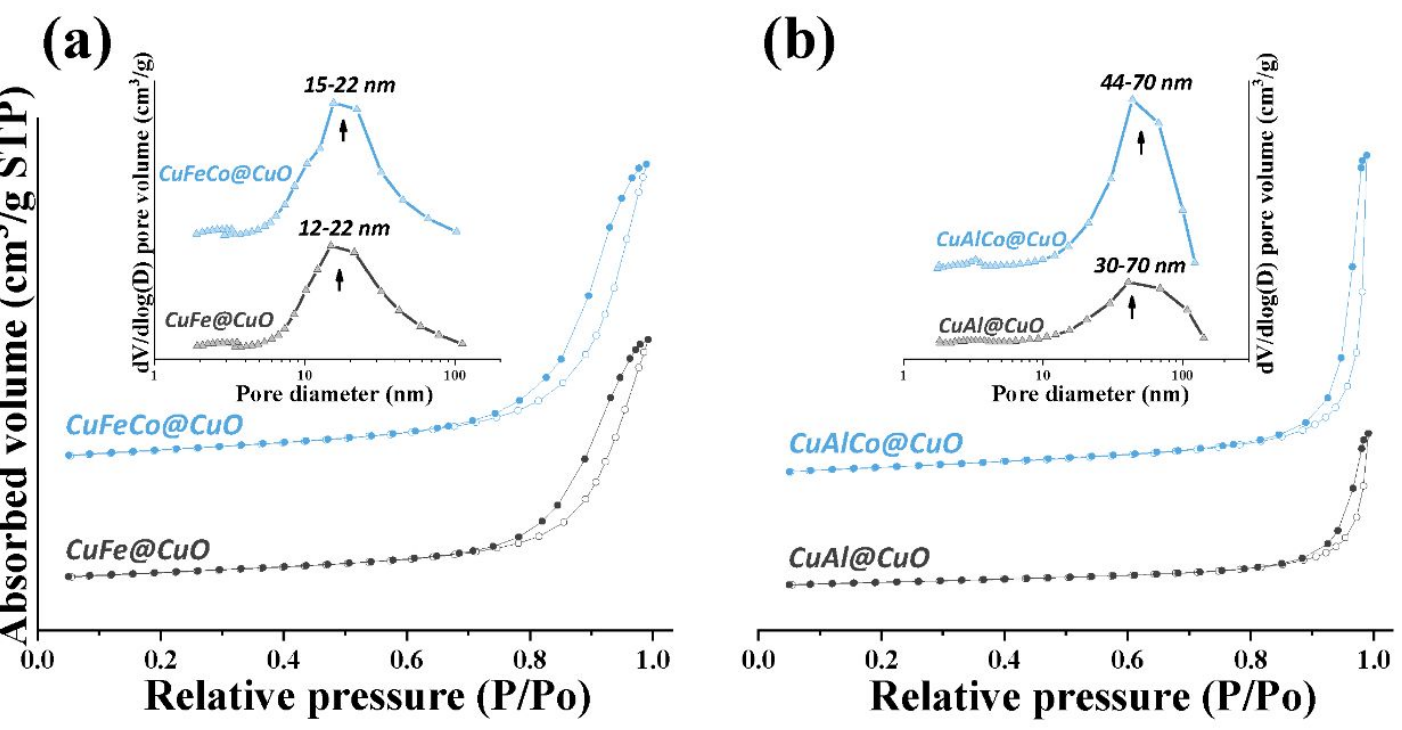

Figure S1. BET isotherms and BJH pore size distribution plots (inset): the (a) $\mathrm{CuFe} @ \mathrm{CuO}$ and CuFeCo@CuO; (b)CuAl@CuO and CuAlCo@CuO. 


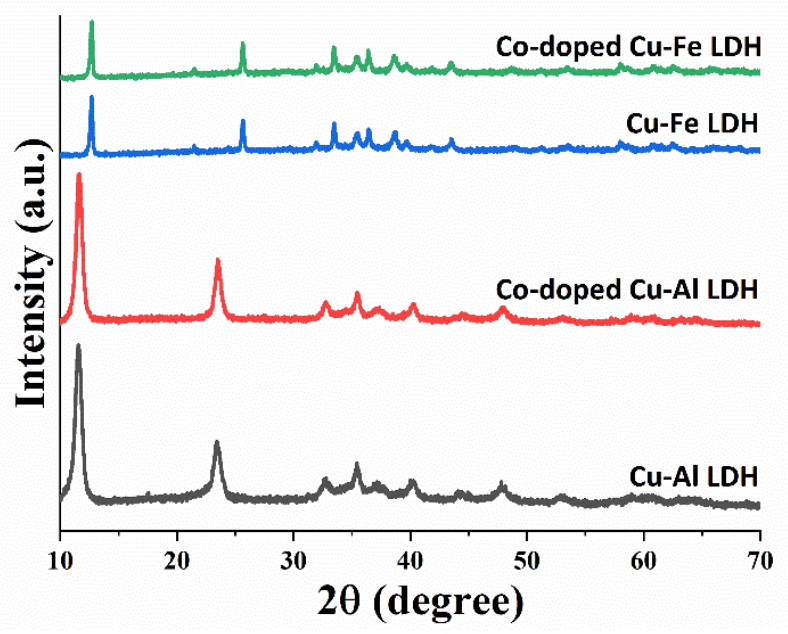

Figure S2. XRD patterns of the LDH precursors. 

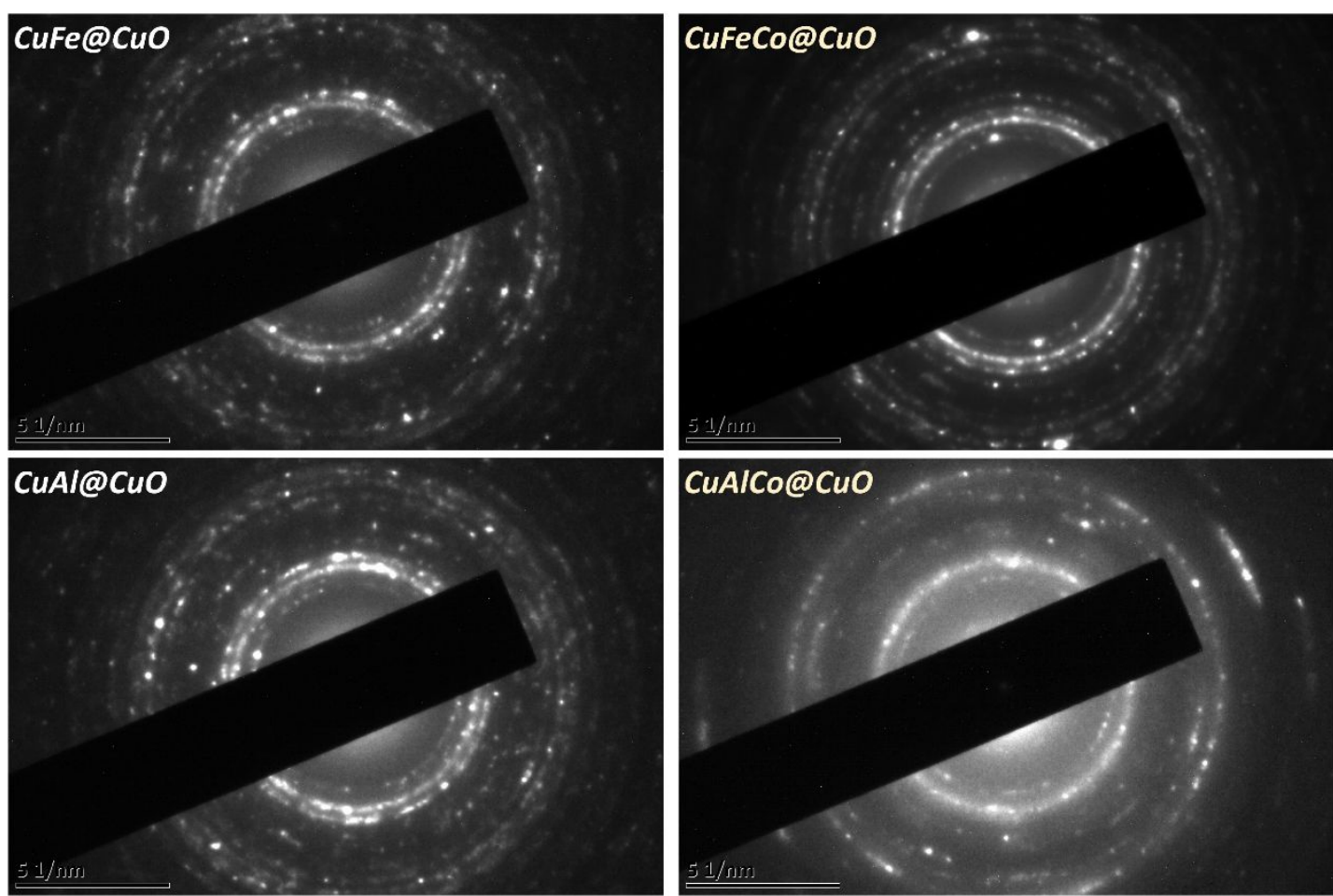

Figure S3. SAED images of the spinel@CuO catalysts. 

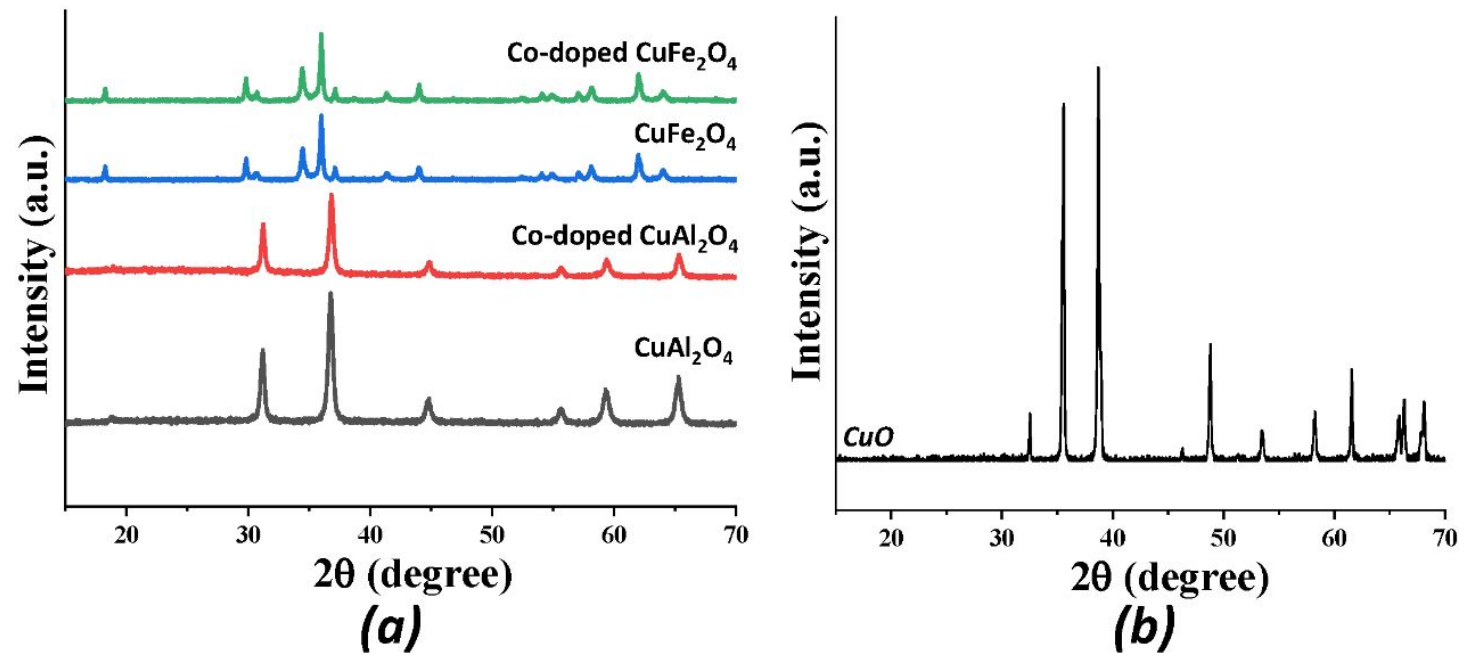

Figure S4. XRD patterns of (a) the spinel samples and (b) $\mathrm{CuO}$ sample. 

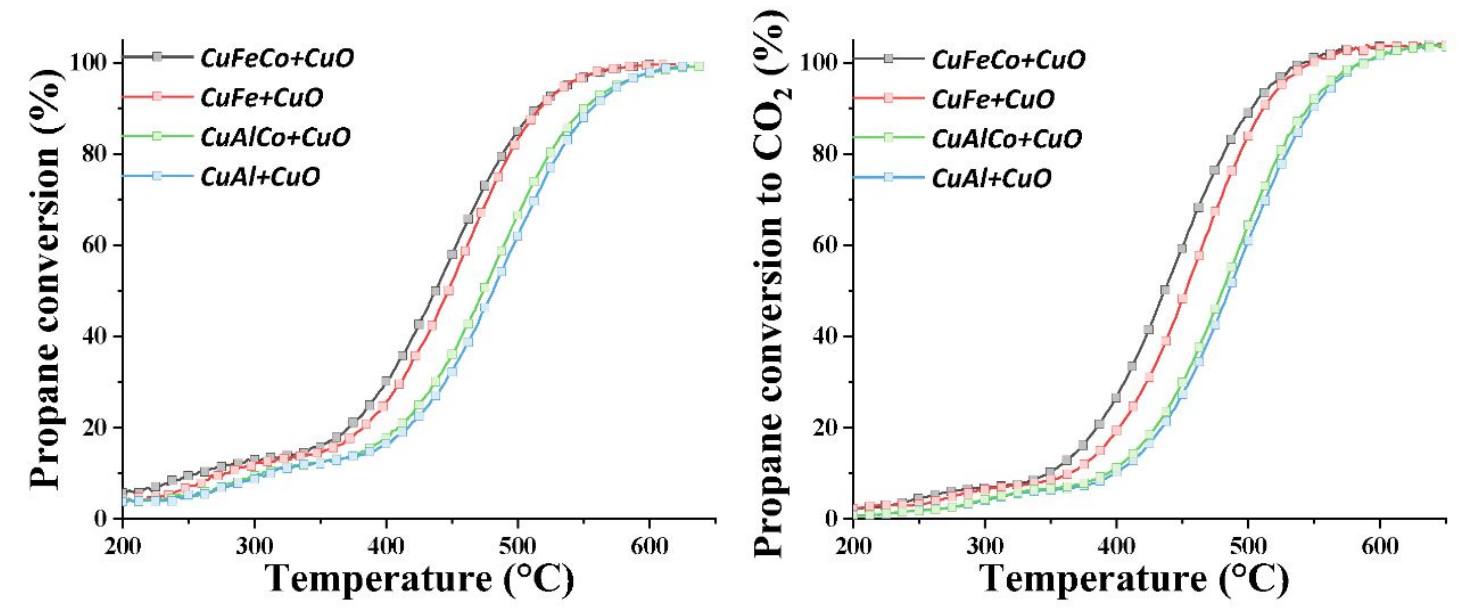

Figure S5. Propane conversion curves and propane conversion to $\mathrm{CO}_{2}$ curves of the physically mixed spinel $+\mathrm{CuO}$ catalysts. 


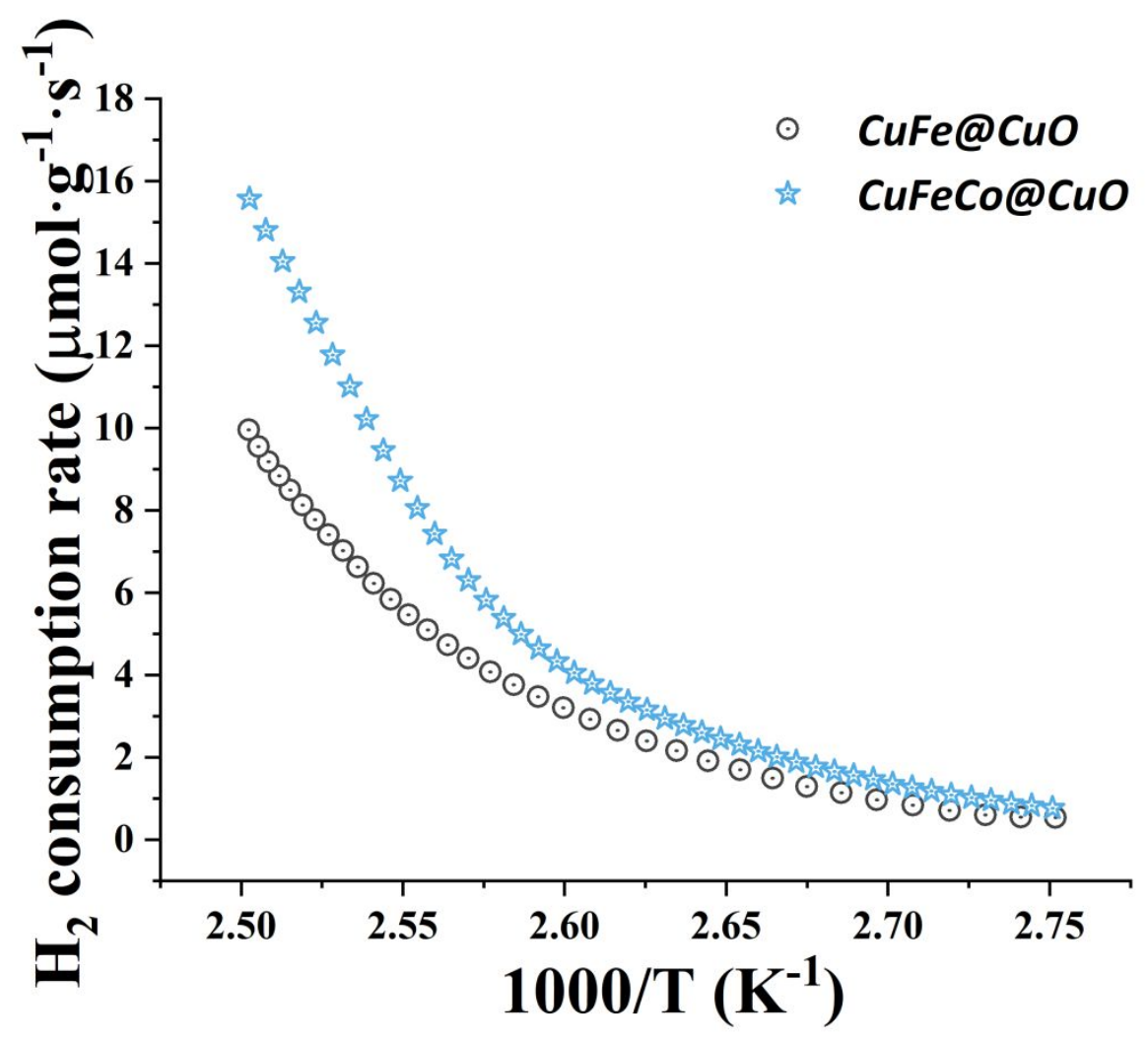

Figure S6. The initial $\mathrm{H}_{2}$ consumption rate versus inverse temperature of the $\mathrm{CuFe} @ \mathrm{CuO}$ and CuFeCo@CuO catalysts. 

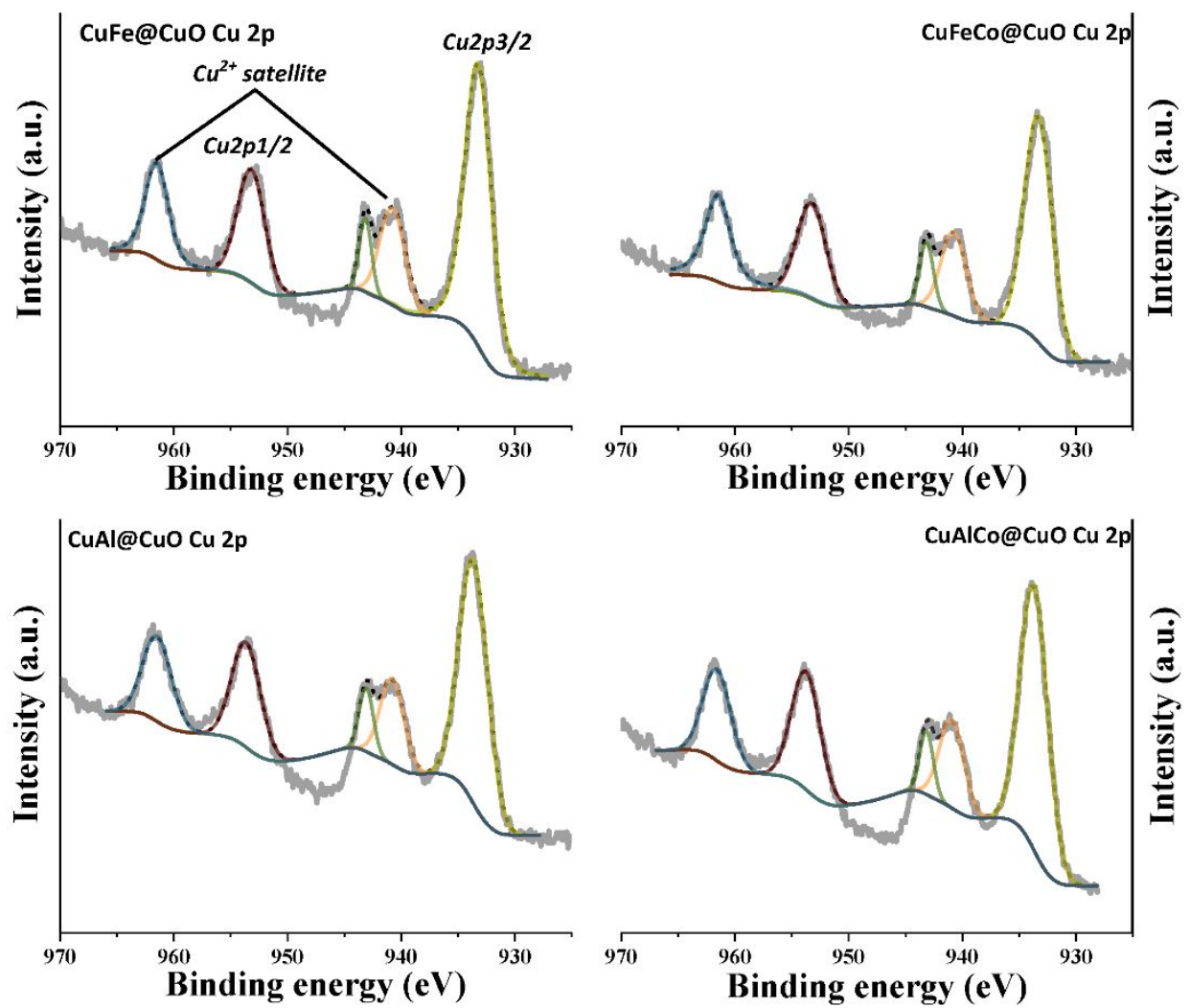

Figure S7. XPS spectra of $\mathrm{Cu} 2 \mathrm{p}$ on the spinel@CuO catalysts. 

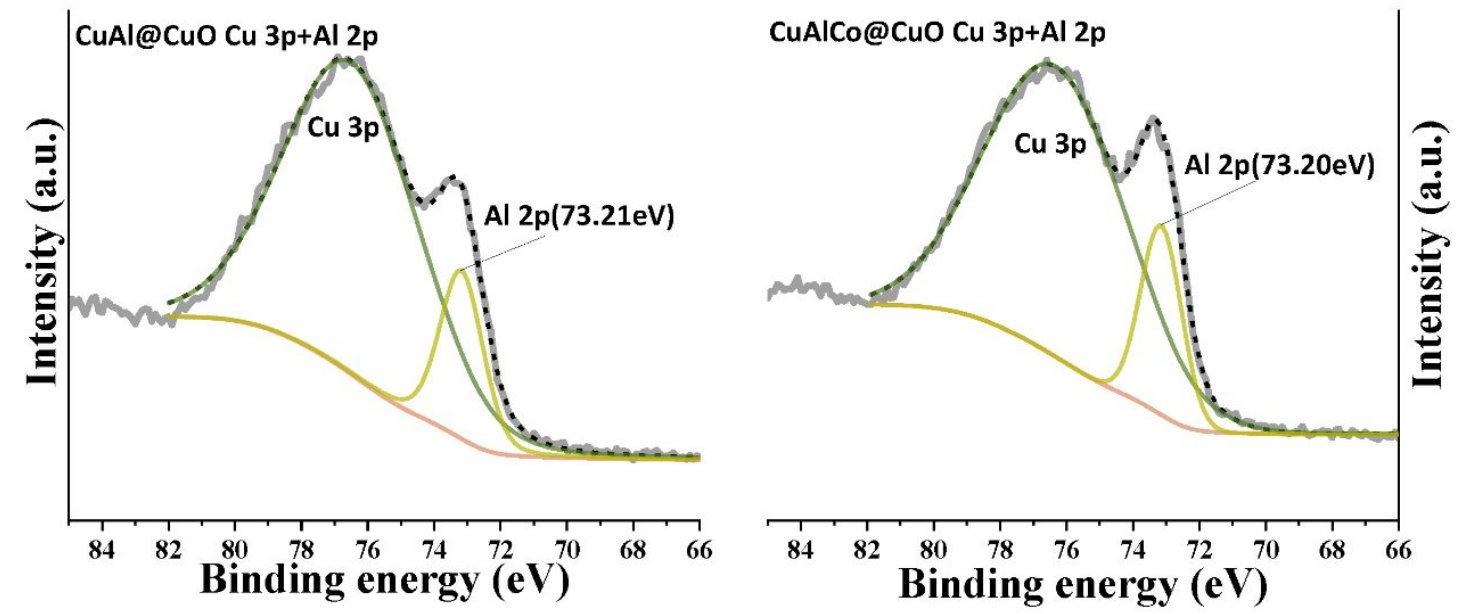

Figure S8. XPS spectra of Al 2p on the CuAl@CuO and CuAlCo@CuO catalysts. 

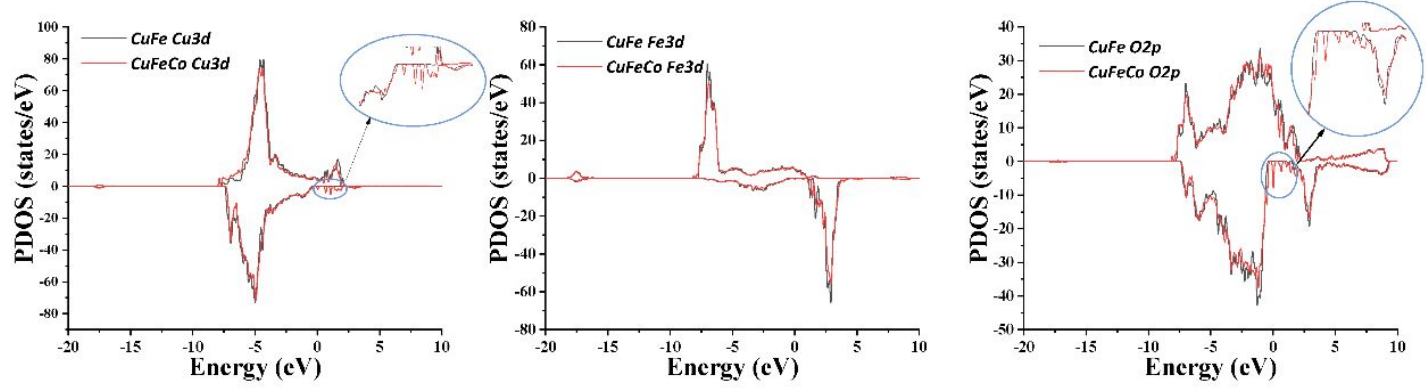

Figure S9. Projected density of states (PDOS) of $\mathrm{Cu} 3 \mathrm{~d}, \mathrm{Fe} 3 \mathrm{~d}$, and $\mathrm{O} 2 \mathrm{p}$ orbitals for the $\mathrm{CuFe}$ and CuFeCo. 

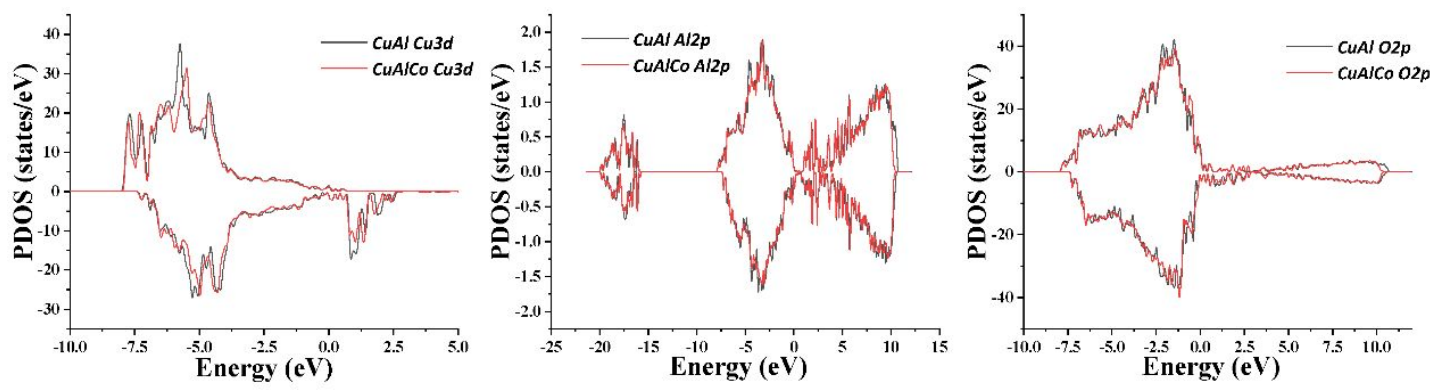

Figure S10. Projected density of states (PDOS) of Cu 3d, Al 2p, and O 2p orbitals for the CuAl and CuAlCo. 

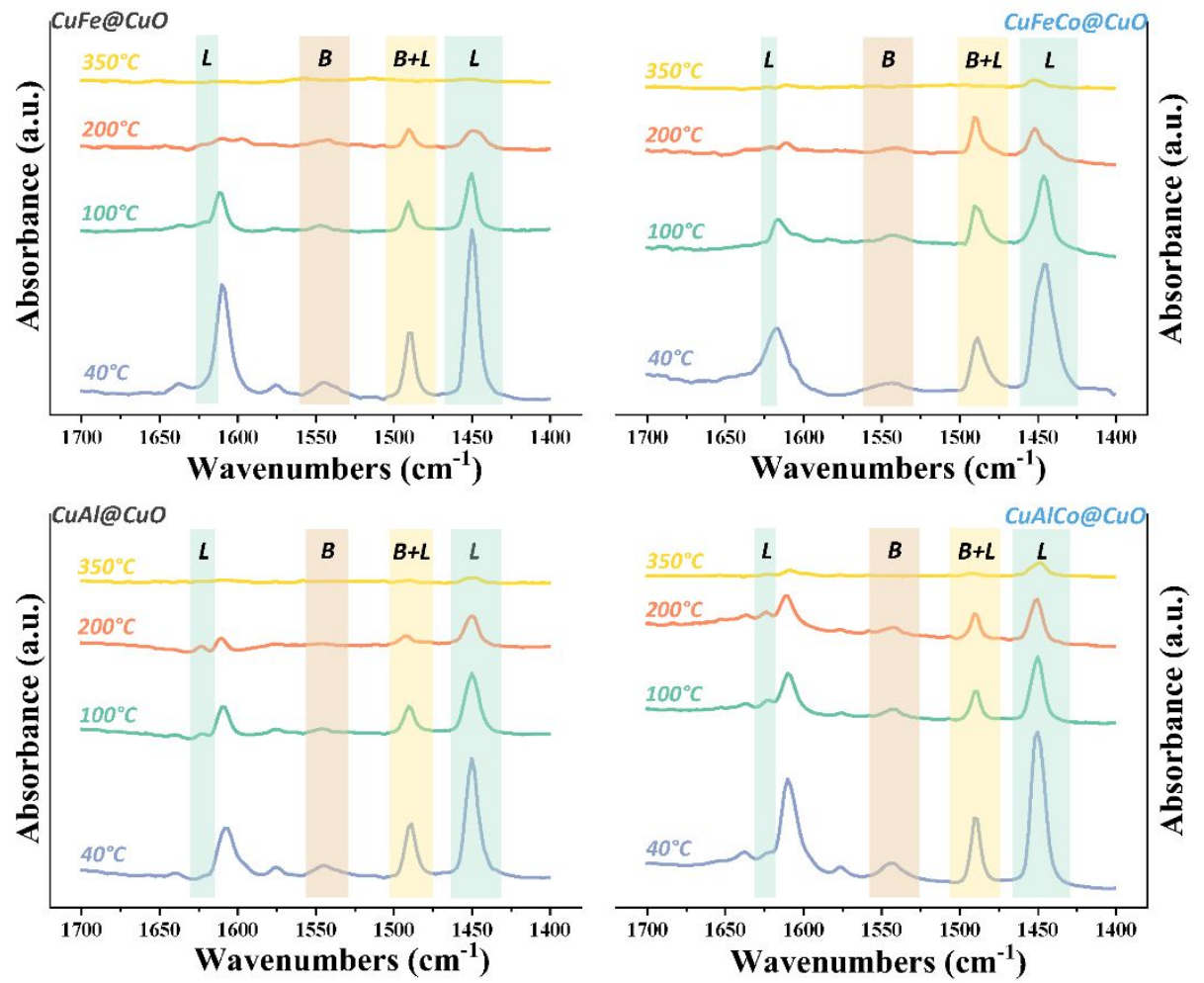

Figure S11. Pyridine-FTIR spectra of the spinel@CuO catalysts at different temperature. 
(a)



(c)

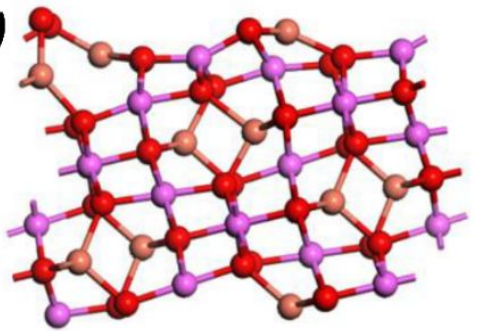

(b)

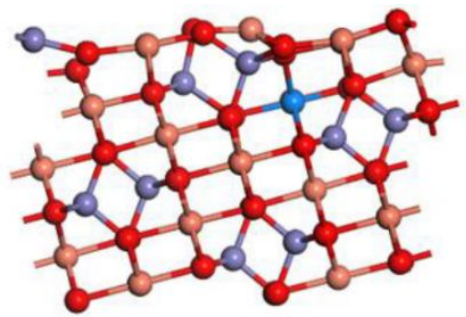

(d)

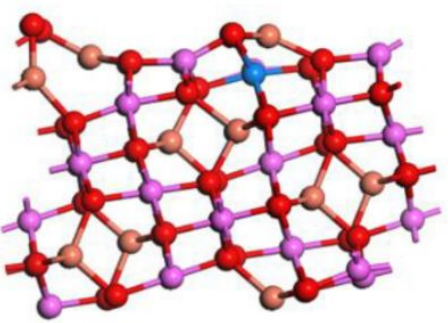

Figure S12. Optimized structure of (a) $\mathrm{CuFe}$, (b) $\mathrm{CuFeCo}$, (c) $\mathrm{CuAl}$, (d) $\mathrm{CuAlCo}$ spinel on side view. The red balls are oxygen, orange balls are copper, deep blue balls are iron, brilliant blue balls are cobalt, and pink balls are aluminium. 
(a)

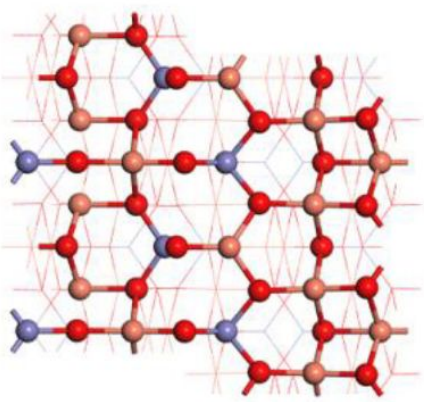

(c)

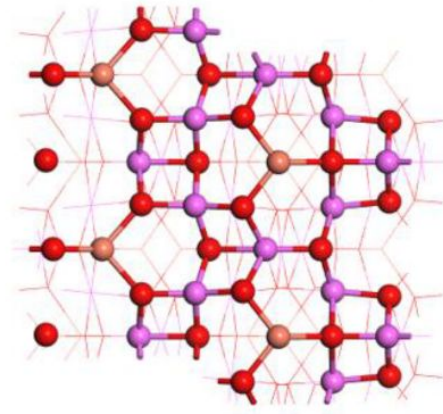

(b)

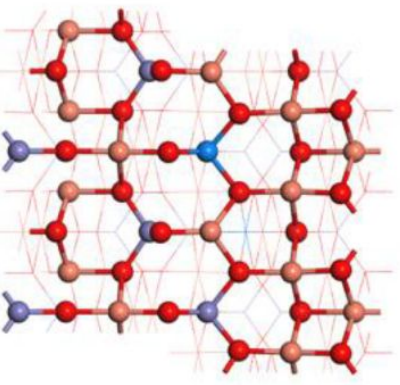

(d)

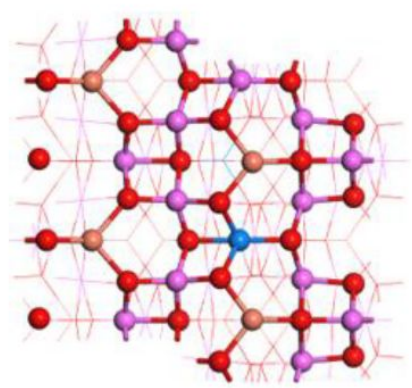

Figure S13. Optimized structure of (a) $\mathrm{CuFe}$, (b) $\mathrm{CuFeCo}$, (c) $\mathrm{CuAl}$, (d) CuAlCo spinel on top view. The red balls are oxygen, orange balls are copper, deep blue balls are iron, brilliant blue balls are cobalt, and pink balls are aluminium. 